\title{
Disability and the Worlds of Welfare Capitalism
}

\author{
Rourke L. O’Brien
}

Harvard University

Abstract: A higher proportion of working- age persons receive disability assistance in the Nordic countries and the Netherlands than in other European countries. Whereas current research emphasizes the connection between disability assistance and rates of labor force exit, to date there has been no exploration of how welfare state context influences individual self-reported disability. Using nationally representative data from 15 countries $(n=88,478)$, I find that residents of generous welfare states are significantly more likely to report a disability net of self-reported health, sociodemographic, and labor force characteristics and, notably, that this association extends to younger and more educated workers. I argue that welfare state context may directly shape what it means to be disabled, which may have consequences for evaluations of welfare state performance and social exclusion.

Keywords: Disability; welfare states; labor markets; health; stratification; identity

Citation: O'Brien, Rourke L. 2015. "Disability and the Worlds of Welfare Capitalism." Sociological Science 2: 1-19.

Received: July 26, 2014

Accepted: September 20, 2014

Published: January 12, 2015

Editor(s): Jesper Sørensen, Stephen L. Morgan

Dol: $10.15195 / \mathrm{v} 2 . \mathrm{a} 1$

Copyright: (C) 2015 The Author(s). This open-access article has been published under a Creative Commons Attribution License, which allows unrestricted use, distribution and reproduction, in any form, as long as the original author and source have been credited. @()
ROSS-NATIONAL studies of individual social, economic, and physical wellbeing consistently demonstrate that residents of northern Europe, particularly the Nordic countries, fare better than their counterparts in other welfare state regimes (Brady, Fullerton, and Cross 2009; Garfinkel, Rainwater, and Smeeding et al. 2010; OECD 2009). Indeed, the Nordic "flexicurity" model—characterized by flexible labor markets coupled with the security of universal and comprehensive social welfare benefits-has been heralded for maintaining labor market competitiveness while shielding citizens from the volatility of global capitalism (Saint-Paul 2004).

At the same time, recent work in labor economics highlights that citizens of northern Europe exit the labor force via disability insurance at a higher rate than their counterparts in other European and North American countries. Studies demonstrate that the relative generosity of disability insurance programs in some countries-notably the Nordic states and the Netherlands-encourage older and less educated workers to exit the labor force onto disability as a form of early retirement or cash assistance, either in lieu of or following a period receiving unemployment benefits. Given the empirical consensus that residents of these countries are among the healthiest in the world (see Olsen and Dahl 2007; OECD 2009), economists assert that the generosity of disability insurance programs for displaced workers, particularly relative to unemployment insurance benefits, is the driving force behind the higher rates of disability assistance in these countries (Borsch-Supan 2007; OECD 2010).

This near singular focus on the labor market consequences of generous disability assistance programs, I argue, obscures the more fundamental question of how welfare state context serves to shape evaluations of what it means to be disabled. Despite recent experimental work suggesting that welfare state context may influence whether respondents consider a set of hypothetical health symptoms as disabling 
(Kapteyan, Smith, and van Soest 2007), there has been no empirical research on how welfare state context may influence whether an individual reports having a disability. Given the strong coincidence of disability and social exclusion, even in wealthy social democratic countries (Jenkins 1991; Elwan 1999), it is critical to identify if and how welfare states may be producing disability, particularly among segments of the population for whom the "pull" of generous disability benefits is weak, such as the employed or highly educated. Documenting this potential externality of welfare state policy is important not only to comparative studies of health and wellbeing but also to understanding the mechanisms through which disability is constructed.

The current investigation seeks to answer two key empirical questions: (1) Net of sociodemographic characteristics and self-reported health, does welfare state context influence individual self-reported disability? and (2) Does this association hold for individuals who are less likely to be influenced by the availability of disability assistance-specifically, individuals who are currently employed or highly educated?

Using individual level data from 15 western European countries, I find a strong association between welfare state context and the odds an individual reports a disability. Specifically, I show that the odds of reporting a disability are significantly higher among residents of Nordic welfare states, net of a host of individual sociodemographic and labor force characteristics. I go on to show that this association is not limited to older or unemployed workers using disability programs as a form of early retirement or cash assistance; indeed, the odds of reporting a disability are higher for Nordic residents across all age cohorts and education levels, and even among those currently employed.

\section{Work, Welfare States, and the Production of Disability}

What it means to be disabled varies over time and across cultures (Haber and Smith 1971; Oliver 1990; Foucault 1963, 1965). Theoretic and comparative explorations of the concept of disability illustrate that notions of disability in modern welfare state economies is largely premised on assessing an individual's ability to work (Oliver 1990; Stone 1984; Jenkins 1991). A given physical or mental condition or disorder might only be considered disabling in contexts where it limits one's ability to participate in gainful employment, either entirely or without accommodation (see Conrad and Barker 2010; Verbrugge and Jette 1994). From its inception, a key mission of the welfare state has been to provide for individuals who cannot achieve self-sufficiency through work due to disability, initially for those injured in war and later for those injured on the factory floor (Skocpol 1995; Stone 1984). Today, the nature of welfare state policies and programs-including those addressing disability-varies widely across countries (Esping-Andersen 1990). Analysis of disability assistance programs by the OECD (2010) produces a regime system that maps closely to the welfare state classification derived by Ferrera (1996), reproduced in Table 1.

Generally, Nordic disability models are characterized by relatively low eligibility barriers and generous cash benefits that are permanent or near-permanent. By 
Table 1: Classification of Welfare State Regimes

\begin{tabular}{llll}
\hline Nordic & Bismarckian & Liberal & Southern \\
\hline Denmark & Austria & Ireland & Italy \\
Finland & Belgium & United Kingdom & Portugal \\
Norway & France & & Spain \\
Sweden & Germany & & \\
& Netherlands & & \\
& Switzerland & & \\
\hline
\end{tabular}

contrast, disability programs in liberal countries are characterized by strict eligibility requirements and smaller stipends that are time limited. Bismarckian countries are considered to be between the liberal and Nordic countries in terms of generosity (although the Netherlands is notably more similar to the Nordic states). Southern countries have less developed programs with lower levels of coverage. Given the differences in program characteristics, spending on disability assistance programs is higher, on average, in the Nordic countries compared to the Bismarckian economies of continental Europe, the liberal Anglo regimes, or the southern economies.

Cross-national studies of program participation demonstrate that the Nordic countries (and the Netherlands) stand out as having the highest rates of disability assistance in Europe: between seven and 11 percent of working-age persons received disability assistance in the Nordic states, compared to less than five percent in France, Germany, and the economies of southern Europe (OECD 2010). This trend has been widely documented in the literature (Bratsberg and Fevang 2010; Koning and van Vurruen 2010; 2007; OECD 2010) and has emerged as a major concern of policymakers. There is compelling evidence that this variation cannot be explained by differences in the health or relative age of national populations. Indeed, crossnational studies of health consistently find that residents of the social democratic or Nordic welfare states of northern Europe are healthier than their counterparts in other European countries (see Bambra 2006; Chung and Muntaner 2007; Coburn 2004; Eikemo et al. 2008; Olsen and Dahl 2007). Estimates of disability-adjusted life years-a composite measure of health quality-constructed by the World Health Organization demonstrate that residents of Sweden and Norway lose fewer years of "healthy" life to illness, injury, and disease than citizens of nearly every other country in the world (WHO 2008). The authors of these studies routinely assert that generous welfare states-characterized by high levels of decommodificationhave positive consequences for the health of the population.

What, then, can explain the higher rates of disability assistance use in the Nordic countries? A study by Borsch-Supan (2007) finds that nearly 75 percent of the variation in rates of disability assistance can be explained by cross-national variation in disability program structure and generosity. Specifically, policy variation along five axes can explain differential rates of assistance: levels of disability insurance coverage; benefit generosity; minimum disability required to be eligible for assistance; strictness of medical assessment; and availability of vocational programs/worker retraining programs. Through simulations, Borsch-Supan demonstrates that hold- 
ing program characteristics constant across European countries would result in significantly lower rates of assistance in the Nordic countries.

Empirical work suggests that the generosity of disability assistance programs in modern economies - and particularly in the Netherlands and Nordic states-makes disability an attractive route for displaced workers. Yet the generosity of these programs and the high proportion of working-age persons receiving benefits may have broader implications for the conception of disability in these societies and, potentially, for the level of invalidity deemed necessary to warrant absence from the labor market and economic assistance from the state. Beyond simply increasing rates of disability assistance, welfare states may actually be influencing what it means to be disabled in these countries relative to other advanced economies.

Recent experimental evidence proves suggestive that this is the case. In one study, Kapteyan, Smith, and van Soest (2007) used a vignette methodology to estimate differences in conceptions of disability between respondents in the United States and the Netherlands. The authors presented identical vignettes to respondents in both countries and asked them to evaluate the severity of the work-limiting disability described. The authors found substantial differences in the degree of "toughness" in the evaluation of disability between the two samples: in evaluating the same scenario, Dutch respondents classified the disability as much more severe than did their American counterparts. The authors argue that this difference in response scales can account for half the difference in the self-reported disability rates between the two countries. Van Soest et al. (2011) build on this work by demonstrating that social network composition accounts for some of this crosscountry variation. Specifically, the authors find that knowing more individuals on disability assistance increases the perceived severity of the disability described in the vignette. This study highlights one pathway through which welfare state policy may shape self-reported disability by shifting social norms about what qualifies as a disability; in countries where rates of disability assistance are high and therefore individuals are more likely to know people who receive disability benefits, the bar for what qualifies as disabling may be lower.

This experimental evidence suggests that the conception of disability is more expansive in countries where rates of disability assistance are high. Yet these studies asked respondents to evaluate the symptoms of a hypothetical other. Do individual conceptions of their own disability status vary across welfare state contexts? And, importantly, is this difference limited to older and more vulnerable workers who may be influenced by the availability of disability assistance, or does it extend to the broader population? These questions are explored in turn below.

\section{Data and Methods}

Data for this study are taken from the European Social Survey (ESS). The ESS is a biennial, cross-sectional, multi-country survey designed to analyze trends in the attitudes and behaviors of citizens in more than 30 countries. This study uses data from the first four rounds of the ESS, with surveys administered in 2002-2003, 2004-2005, 2006-2007, and 2008-2009. The sample is limited to respondents in the 
15 countries of focus between the ages of 16 and 64 (inclusive), yielding an analytic sample of 88,795 respondents.

The availability of a singular measure of disability that is comparable across countries makes the ESS unique among surveys typically used in comparative research. Disability is coded based on an individual's response to the question, "Are you hampered in your daily activities in any way by any longstanding illness, or disability, infirmity, or mental health problem?" Available responses are "No," "Yes-to some extent," and "Yes-a lot." Those who responded yes (either "to some extent" or "a lot") are coded as having a disability, resulting in a dichotomous indicator of self-reported disability. Unfortunately the ESS does not include information about whether an individual currently receives or has ever received disability benefits, so it is not possible to identify those individuals in the sample.

Given the range of languages spoken in the countries surveyed, administrators of the ESS employ a rigorous protocol to ensure the harmonization of questions and concepts. This includes a multi-stage, iterative, "team-based" translation process whereby survey questions drafted in British English are first translated by researchers in the host country and then considered by an advisory board in that language to ensure clarity and conceptual integrity (see Harkness 2007; Fitzgerald and Jowell 2011). The questionnaires are then pre-tested separately in every language. The structure of the questionnaire-including the ordering of specific items-is constant across countries and languages. On the disability item specifically, additional guidance is provided to the translation teams to clarify that the English word "hampered" in this context denotes "limited, restricted in your daily activities."

Country is coded using current country of residence. Self-reported health is coded as a series of five dummy variables (very bad, bad, fair, good, very good). Sociodemographic predictors include linear and quadratic measures for age, a continuous measure of household size, and dummy indicators for sex, nativity status, minority status within country, and whether respondent is married. Education is coded as a series of six dummy variables demarcating a harmonized treatment of education levels across countries (less than lower secondary education; lower secondary education completed;upper secondary education completed; post-secondary non-tertiary education completed; tertiary education completed; other).

Labor force variables include indicators for whether the respondent is currently employed or retired and indicators for whether an individual has ever experienced an unemployment spell lasting longer than three months. Given the link between occupation and disability, models presented below include 493 dummy indicators for respondent's occupation, including an indicator for those who do not have or do not report an occupation. Because many occupation codes include a small number of respondents, some occupations perfectly predict the outcome (of disability), and therefore a coefficient cannot be estimated; those respondents are dropped from the sample, resulting in a loss of 125 cases. Alternative model specifications using broader occupational groupings (ten in total) yield substantively identical results (see Table $\mathrm{C}$ in the online supplement). Weighted means or proportions for all covariates used in the analysis are available in Table A in the online supplement. 
Self-reported disability is predicted using logistic regression. In each model the reference category is the grand mean of all countries in the model. ${ }^{1}$ Using the grand mean as the reference category permits the coefficients for each individual country dummy to be interpreted relative to the unweighted average of all countries in the model. A clear benefit of this modeling strategy in cross-national research is that country-specific coefficients can be interpreted as deviations from the grand mean of all countries in the group, not in relation to an arbitrarily defined reference country. Findings are robust to alternative modeling strategies, as discussed below.

Model 1 predicts self-reported disability using country dummy variables and self-reported health. Model 2 includes sociodemographic variables. Models 3 adds labor force variables. Indicators for survey round are included in each model. Subsequent models explore the association between welfare state context and selfreported disability on subsets of the sample by age and level of education. All analyses are limited to respondents of working age (between 16 and 64, inclusive) and employ country-level weights to account for differential sampling designs at the country level; standard errors are clustered at the country level. Missing data is dealt with using listwise deletion unless noted above; less than 0.3 percent of the data is missing on the key measure of disability, and in the fully specified models only 1.6 percent of the sample (1,456 cases) is dropped due to missing data on any of the demographic or labor force measures.

\section{Results}

\section{Descriptive Statistics}

Figure 1 displays the proportion of working-age individuals reporting a disability by country. The graphic shows that there is considerable cross-national variation in the proportion of working-age persons reporting a disability, with nine percent reporting a disability in Italy and Spain, compared to 25 percent and 23 percent in Finland and Sweden respectively. The ranking of countries by proportion of individuals reporting a disability maps well on to the ranking of countries by proportion of working-age individuals receiving disability assistance presented in Figure 2. The Nordic countries and the Netherlands appear to have among the highest rates of disability assistance in Europe as well as the highest proportion of working-age persons who identify as having a disability. It is important to note that while there are trends across welfare state regimes-with the Nordic and Bismarckian countries posting consistently higher rates of disability compared to the southern countries-there exists considerable variation within classifications as well. Among Bismarckian countries, for example, Switzerland posts a low rate of 15 percent, compared to 22 percent in the Netherlands. Nevertheless, the tight clustering of disability rates within the Nordic and southern regimes provides some evidence of a real difference across policy regimes.

As detailed above, the existing empirical literature has focused largely on the role of disability insurance programs as a means of labor force exit for older and more vulnerable workers. If generous disability policies were only serving as a vehicle for early retirement, we might expect that the overall difference in the 


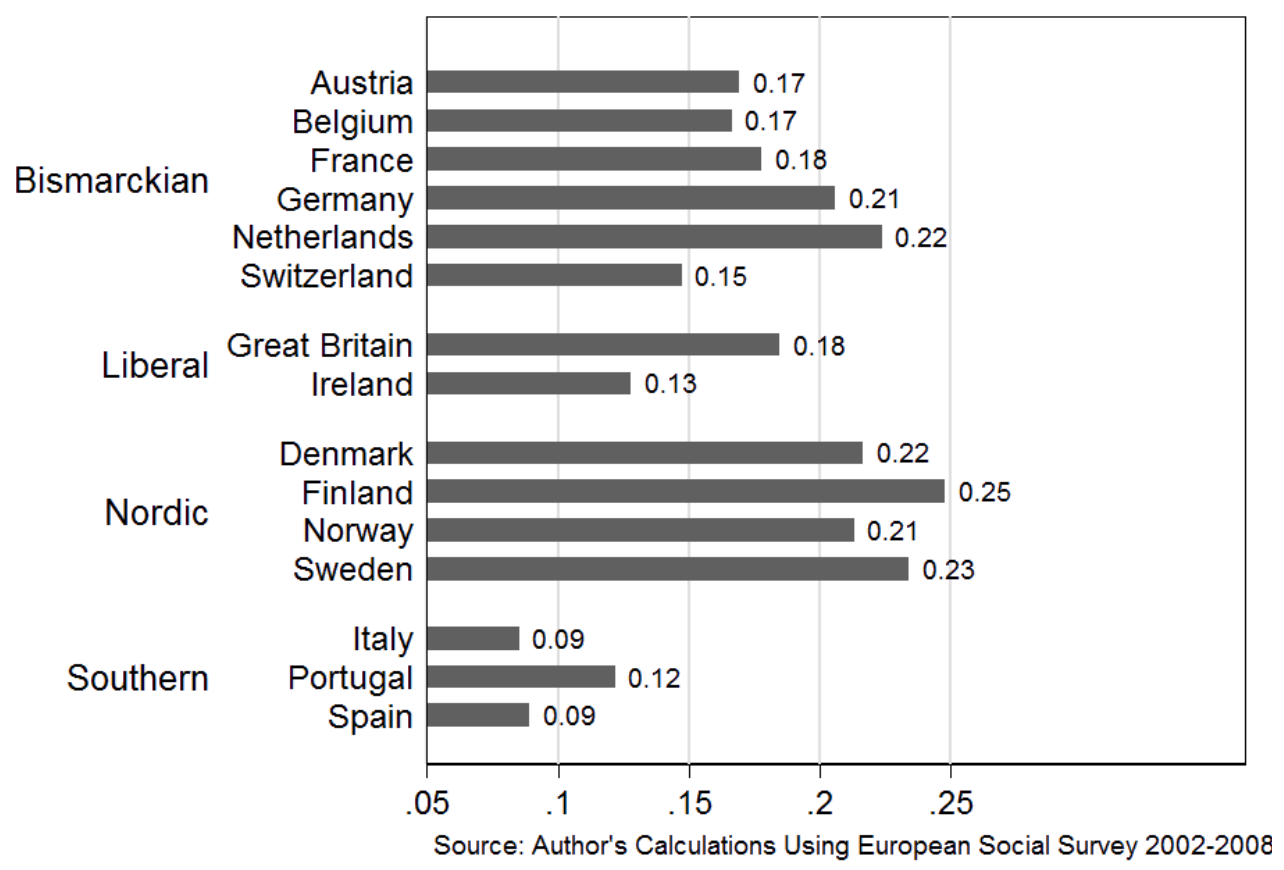

Figure 1: Proportion of Working Age Adults Reporting Disability

disability rates between the Nordic countries and the rest of Europe is driven by a large disparity in the disability rates among those approaching retirement age. Figure 2 demonstrates that this is not the case. As expected, rates of disability increase with age in all welfare state regimes. Yet, in every age cohort, the residents of Nordic countries post a significantly higher rate of disability than residents of other European countries. Even among the youngest cohort, individuals between the ages of 16 and 29 , the percentage reporting a disability in the Nordic countries is five percentage points higher than in the Bismarckian countries and nine percentage points higher than among residents of southern Europe. These basic descriptives suggest that the association between welfare state regime policy and disability extends beyond increased rates of labor force exit by older workers; welfare state policy regimes appear to be associated with higher rates of disability among workers in their 40s and younger.

Figure 3 presents the proportion of working-age persons reporting a disability, restricting the sample to those who have completed tertiary education (i.e., have a college degree). We would expect the pull of disability assistance programs to be lower for this highly educated subgroup. As expected, disability rates are generally lower among those with more education compared with the overall population in each country. Yet, again, rates of disability among those with a college education are considerably and consistently higher in the Nordic countries, with Finland leading all countries with 22 percent of this subsample reporting a disability. Between 20 and 22 percent of the population of Nordic countries without a secondary degree report a disability, compared to between 5 percent and 6 percent of their counterparts in southern Europe. Notably, both Germany and the Netherlands post disability rates 


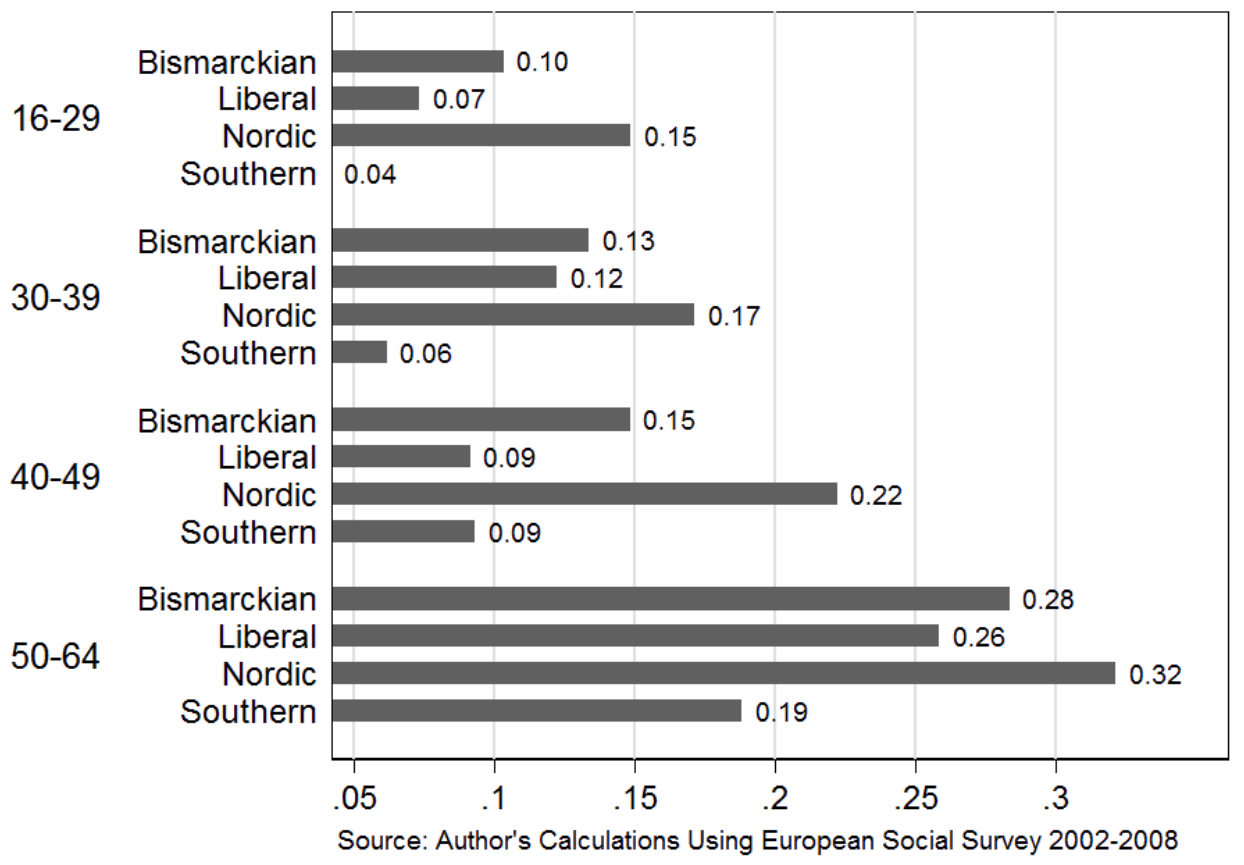

Figure 2: Proportion of Working Age Adults Reporting Disability by Age

among the highly educated that are closer to the Nordic countries than the other Bismarckian states.

Taken together, these figures demonstrate considerable cross-national variation in the proportion of the working-age population reporting a disability. What's more, there appears to be a real difference in rates of disability by welfare state regime types, with the Nordic countries posting considerably higher rates of disability than the rest of Europe, including for younger cohorts and among highly educated workers. Although weighted to be nationally representative, these descriptive statistics do not account for any of the sociodemographic or labor force variables that have been documented to play an important role in determining an individual's perception of their own disabilities. The next set of analyses seeks to analyze whether this cross-national and cross-welfare regime pattern of disability holds net of individual-level characteristics.

\section{Regression Analyses}

Results from the first set of multivariate logistic regression models predicting self-reported disability are presented in Table 2. For each model, the reference category for the country coefficients is the unweighted grand mean of all of the country coefficients. That is, each country-specific coefficient is a measure of how an individual's odds of reporting a disability in that particular country compares with the unweighted average odds across all countries. Model 1 predicts selfreported disability by country controlling for individual's self-reported health and the survey round. Evaluation of the coefficients reveals a stark pattern: residents of 


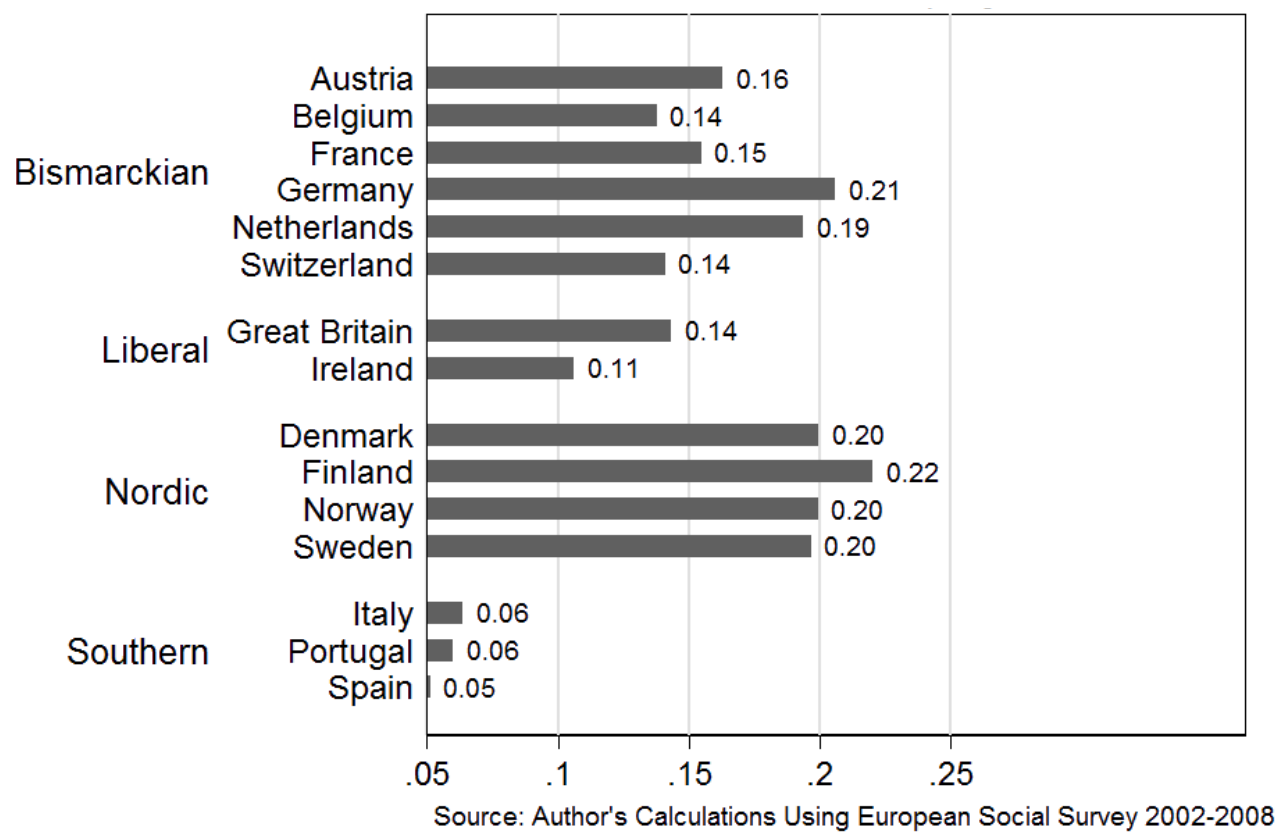

Figure 3: Proportion of Working Age Adults with Tertiary Degree Reporting Disability

Nordic European countries have significantly higher odds of reporting a disability, and residents of southern European countries have significantly lower odds of reporting a disability, compared to the average across all countries. The liberal and Bismarckian countries fall in between these two extremes, with residents of France posting 23 percent lower odds relative to the European average, Germany posting 23 percent higher odds, and residents of the Netherlands posting 59 percent higher odds.

Model 2 builds on the previous regression with the inclusion of a broad set of sociodemographic variables including age, education, marital status, citizenship, and minority status. Notably, the addition of these individual-level covariates does not change the relative size of coefficients for individual country-level indicators. Model 3 adds individual-level labor force covariates, including employment status and a full complement of industry occupation codes. Again the coefficients for country of residence tell the same story: net of a host of individual-level sociodemographic and labor force characteristics, individuals in Nordic countries are more likely to report having a disability than their peers in liberal or Bismarckian countries, and much more likely than their counterparts residing in southern Europe.

Taken together, there are two compelling patterns to note. First is the pattern of coefficients across models: the magnitude of differences across welfare state regimes and across countries is largely unchanged, even after controlling for individuallevel sociodemographic and labor force characteristics. Second is the clustering of country coefficients within welfare state regime categories: for example, in model 3, the odds of reporting a disability are between 71 percent and 134 percent higher in the Nordic countries and between 73 percent and 75 percent lower in the southern countries, relative to the European average. Although the liberal countries 
Table 2: Logistic Models Predicting Self-Reported Disability of Working Age Population by Country of Residence

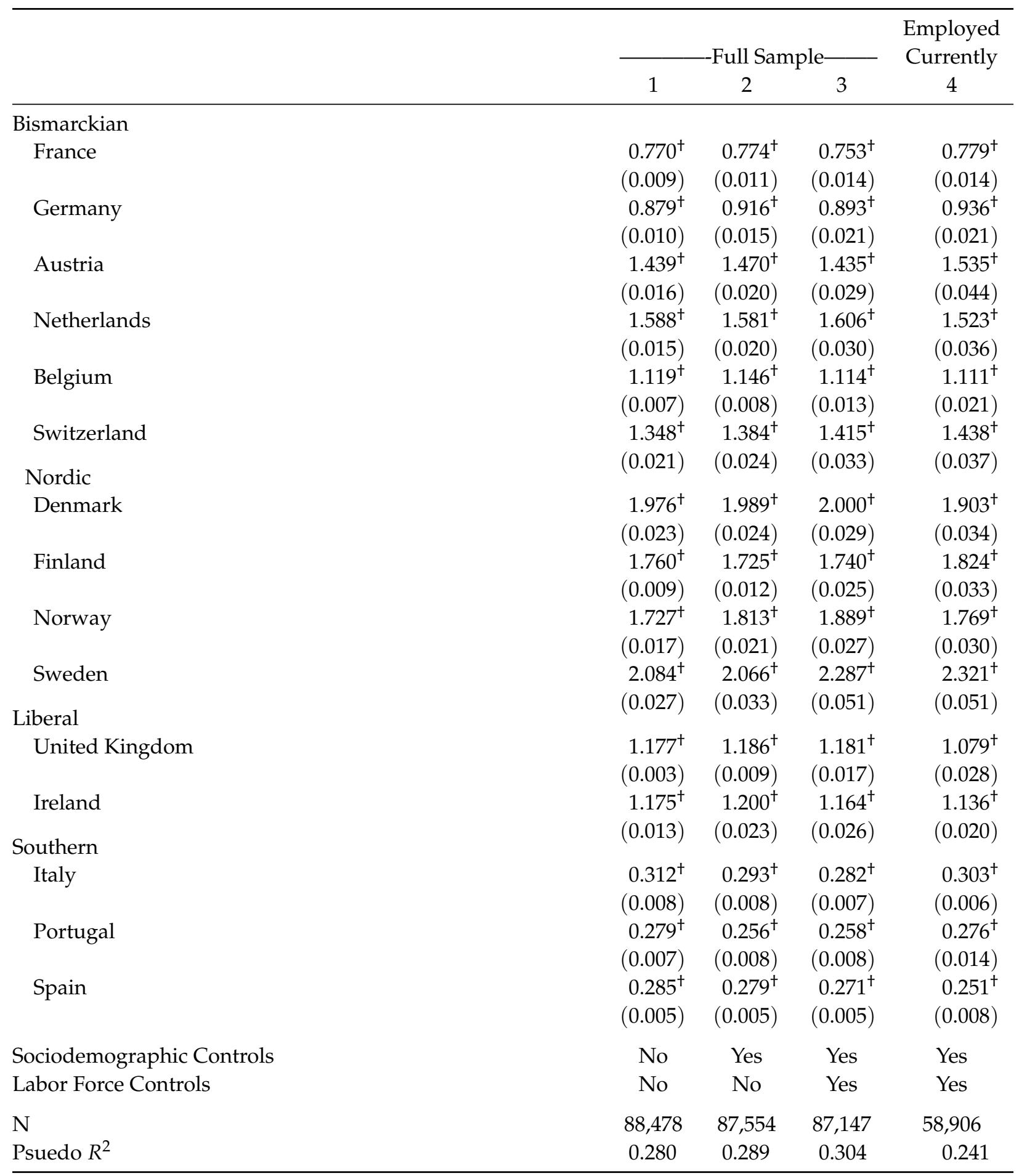

Notes: All models control for self-reported health. Survey round controlled for in all models. Reference is average of all countries in the model. Survey weights used. Standard errors clustered by country. $+p<0.01$. 
overlap with the Bismarckian range, the similarity in the coefficients between the United Kingdom and Ireland suggest a coherent and distinct regime in these Anglo countries.

Still, it may be argued that this modeling simply reflects cross-national trends in rates of disability assistance, as countries with higher proportions of their population receiving disability assistance are more likely to have a higher proportion of residents identifying as having a disability. Model 4 explores whether differences in welfare state regimes influence self-perceptions of disability among those not likely to be currently receiving benefits by restricting the sample to individuals who are currently employed. Here again the same pattern emerges: even among those currently employed-and therefore not likely to be receiving welfare benefits contingent on disability - the odds of reporting a disability are substantially higher among residents of Nordic countries compared to the rest of western Europe.

The degree to which an individual's perception of his or her own disability can be influenced by social welfare policies is contingent upon, at least in part, the degree to which they are vulnerable to-or sheltered from-labor market conditions. As noted above, less educated individuals are more likely to report a disability and exit the labor force onto disability assistance than individuals with more education, regardless of country. At the same time, disability rates increase with age, as does the likelihood an individual will exit the labor force via disability. It is therefore worthwhile to analyze the degree to which cross-national variation in disability is driven by distributional differences in self-reported disability along these two axes.

Table 3 presents three models predicting self-reported disability by country of residence, subsetting the sample by those with less than a secondary degree, those with a secondary degree, and those with schooling beyond a secondary degree. These education measures have been standardized across countries in the ESS. Across all three models, a familiar pattern emerges: individuals in the Nordic countries have higher odds of reporting a disability than residents of other European countries.

Again, it may be argued that this association between welfare state generosity and self-reported disability is driven largely by higher rates of labor force exit onto disability by older workers as a form of early retirement. This is certainly an important trend, and the implications for policy and evaluation of welfare state externalities would be more limited if the association was restricted to this group. However, the models presented in Table 4 suggest that the association is not restricted to older cohorts. Models 5-8 predict disability on subsets of age using the full host of individual sociodemographic and labor force controls employed in the previous models. These models reveal that the pattern of disability in the aggregated sample is played out at every age: residents of Nordic countriesyoung and old-have significantly higher odds of reporting a disability than their counterparts in the rest of Europe.

The country level coefficients presented in the above models are useful in providing a sense of the relative magnitude of the association between country of residence and likelihood of reporting a disability. However, these coefficients are estimated in reference to the European average. The relative size of coefficients is therefore in part an artifact of which countries are included in the model as this 
Table 3: Logistic Models Predicting Self-Reported Disability By Age and Country of Residence

\begin{tabular}{|c|c|c|c|c|}
\hline & $\begin{array}{c}\text { Age } 16-29 \\
\text { (5) }\end{array}$ & $\begin{array}{c}\text { Age } 30-39 \\
\text { (6) }\end{array}$ & $\begin{array}{c}\text { Age } 40-49 \\
\text { (7) }\end{array}$ & $\begin{array}{c}\text { Age } 50-64 \\
\text { (8) }\end{array}$ \\
\hline \multicolumn{5}{|l|}{ Bismarckian } \\
\hline \multirow[t]{2}{*}{ France } & $0.890^{\dagger}$ & $0.831^{+}$ & $0.714^{\dagger}$ & $0.698^{\dagger}$ \\
\hline & $(0.045)$ & $(0.031)$ & $(0.026)$ & $(0.018)$ \\
\hline \multirow[t]{2}{*}{ Germany } & 0.951 & $0.760^{\dagger}$ & $0.822^{\dagger}$ & 0.962 \\
\hline & $(0.033)$ & $(0.019)$ & $(0.039)$ & $(0.030)$ \\
\hline \multirow[t]{2}{*}{ Austria } & $1.187^{\dagger}$ & $1.386^{+}$ & $1.451^{\dagger}$ & $1.674^{+}$ \\
\hline & $(0.040)$ & $(0.051)$ & $(0.053)$ & $(0.045)$ \\
\hline \multirow[t]{2}{*}{ Netherlands } & $1.614^{\dagger}$ & $1.695^{\dagger}$ & $1.624^{\dagger}$ & $1.557^{\dagger}$ \\
\hline & $(0.094)$ & $(0.050)$ & $(0.042)$ & $(0.043)$ \\
\hline \multirow[t]{2}{*}{ Belgium } & $1.129^{\dagger}$ & $1.155^{+}$ & 1.016 & $1.123^{+}$ \\
\hline & $(0.032)$ & $(0.031)$ & $(0.036)$ & $(0.026)$ \\
\hline \multirow[t]{2}{*}{ Switzerland } & $1.434^{+}$ & $1.312^{\dagger}$ & $1.321^{\dagger}$ & $1.568^{\dagger}$ \\
\hline & \multicolumn{2}{|c|}{ Nordic } & $(0.051)$ & $(0.046)$ \\
\hline \multirow[t]{2}{*}{ Denmark } & $1.944^{\dagger}$ & $2.077^{\dagger}$ & $1.988^{\dagger}$ & $2.036^{+}$ \\
\hline & $(0.067)$ & $(0.064)$ & $(0.073)$ & $(0.044)$ \\
\hline \multirow[t]{2}{*}{ Finland } & $2.062^{\dagger}$ & $2.103^{+}$ & $1.750^{\dagger}$ & $1.588^{\dagger}$ \\
\hline & $(0.065)$ & $(0.065)$ & $(0.041)$ & $(0.044)$ \\
\hline \multirow[t]{2}{*}{ Norway } & $1.802^{\dagger}$ & $2.122^{+}$ & $2.072^{\dagger}$ & $1.816^{\dagger}$ \\
\hline & $(0.066)$ & $(0.084)$ & $(0.065)$ & $(0.054)$ \\
\hline \multirow[t]{2}{*}{ Sweden } & $1.975^{+}$ & $2.097^{+}$ & $2.640^{\dagger}$ & $2.631^{\dagger}$ \\
\hline & \multicolumn{4}{|c|}{ Liberal } \\
\hline \multirow{2}{*}{ United Kingdom } & $0.783^{\dagger}$ & $1.206^{\dagger}$ & 1.043 & $1.626^{\dagger}$ \\
\hline & $(0.016)$ & $(0.048)$ & $(0.034)$ & $(0.037)$ \\
\hline \multirow[t]{2}{*}{ Ireland } & 1.052 & $1.244^{+}$ & $1.129^{\dagger}$ & $1.202^{\dagger}$ \\
\hline & \multicolumn{4}{|c|}{ Southern } \\
\hline \multirow[t]{2}{*}{ Italy } & $0.357^{\dagger}$ & $0.205^{\dagger}$ & $0.303^{+}$ & $0.245^{\dagger}$ \\
\hline & $(0.023)$ & $(0.021)$ & $(0.019)$ & $(0.011)$ \\
\hline \multirow[t]{2}{*}{ Portugal } & $0.357^{+}$ & $0.274^{+}$ & $0.275^{\dagger}$ & $0.184^{\dagger}$ \\
\hline & $(0.013)$ & $(0.019)$ & $(0.021)$ & $(0.007)$ \\
\hline \multirow[t]{2}{*}{ Spain } & $0.254^{+}$ & $0.271^{+}$ & $0.288^{\dagger}$ & $0.237^{\dagger}$ \\
\hline & $(0.010)$ & $(0.010)$ & $(0.012)$ & $(0.006)$ \\
\hline Sociodemographic Controls & Yes & Yes & Yes & Yes \\
\hline Labor Force Controls & Yes & Yes & Yes & Yes \\
\hline $\mathrm{N}$ & 19,721 & 19,305 & 20,463 & 26,999 \\
\hline Psuedo $R^{2}$ & 0.227 & 0.300 & 0.307 & 0.320 \\
\hline
\end{tabular}

Notes: Survey round controlled for in all models. Reference is average of all countries in the model. Survey weights used. Standard errors clustered by country.

$+p<0.01$. 
Table 4: Logistic Models Predicting Disability Status by Country of Residence and Level of Education

\begin{tabular}{|c|c|c|c|}
\hline & $\begin{array}{l}\text { Less than } \\
\text { Secondary } \\
\text { (9) }\end{array}$ & $\begin{array}{c}\text { Secondary } \\
\text { (10) }\end{array}$ & $\begin{array}{c}\text { Post- } \\
\text { Secondary } \\
(11)\end{array}$ \\
\hline \multicolumn{4}{|l|}{ Bismarckian } \\
\hline France & $\begin{array}{c}0.700^{+} \\
(0.014)\end{array}$ & $\begin{array}{c}0.710^{\dagger} \\
(0.017)\end{array}$ & $\begin{array}{r}0.862^{\dagger} \\
(0.025)\end{array}$ \\
\hline Germany & $\begin{array}{l}1.032 \\
(0.037)\end{array}$ & $\begin{array}{r}0.837^{\dagger} \\
(0.027)\end{array}$ & $\begin{array}{r}0.896^{\dagger} \\
(0.040)\end{array}$ \\
\hline Austria & $\begin{array}{r}1.355^{\dagger} \\
(0.042)\end{array}$ & $\begin{array}{c}1.543^{\dagger} \\
(0.049)\end{array}$ & $\begin{array}{r}1.215^{\dagger} \\
(0.047)\end{array}$ \\
\hline Netherlands & $\begin{array}{c}1.582^{+} \\
(0.040)\end{array}$ & $\begin{array}{r}1.755^{\dagger} \\
(0.049)\end{array}$ & $\begin{array}{c}1.654^{+} \\
(0.041)\end{array}$ \\
\hline Belgium & $\begin{array}{l}1.097^{+} \\
(0.017)\end{array}$ & $\begin{array}{l}1.070^{+} \\
(0.018)\end{array}$ & $\begin{array}{r}1.166^{\dagger} \\
(0.030)\end{array}$ \\
\hline Switzerland & $\begin{array}{l}1.311^{\dagger} \\
(0.062)\end{array}$ & $\begin{array}{r}1.415^{+} \\
(0.050)\end{array}$ & $\begin{array}{c}1.611^{\dagger} \\
(0.047)\end{array}$ \\
\hline Denmark & $\begin{array}{r}2.212^{+} \\
(0.072)\end{array}$ & $\begin{array}{c}1.843^{+} \\
(0.038)\end{array}$ & $\begin{array}{c}2.118^{\dagger} \\
(0.045)\end{array}$ \\
\hline Finland & $\begin{array}{c}1.657^{+} \\
(0.060)\end{array}$ & $\begin{array}{l}1.747^{\dagger} \\
(0.037)\end{array}$ & $\begin{array}{r}1.859^{\dagger} \\
(0.038)\end{array}$ \\
\hline Norway & $\begin{array}{c}2.010^{+} \\
(0.053)\end{array}$ & $\begin{array}{r}2.042^{+} \\
(0.046)\end{array}$ & $\begin{array}{r}1.757^{\dagger} \\
(0.050)\end{array}$ \\
\hline $\begin{array}{l}\text { Sweden } \\
\text { Liberal }\end{array}$ & $\begin{array}{r}2.353^{+} \\
(0.069)\end{array}$ & $\begin{array}{r}2.237^{+} \\
(0.067)\end{array}$ & $\begin{array}{r}2.293^{\dagger} \\
(0.061)\end{array}$ \\
\hline United Kingdom & $\begin{array}{c}1.168^{\dagger} \\
(0.021)\end{array}$ & $\begin{array}{c}1.097^{+} \\
(0.026)\end{array}$ & $\begin{array}{r}1.258^{\dagger} \\
(0.047)\end{array}$ \\
\hline Ireland & $\begin{array}{l}1.070^{*} \\
(0.030)\end{array}$ & $\begin{array}{c}1.182^{+} \\
(0.035)\end{array}$ & $\begin{array}{r}1.340^{\dagger} \\
(0.055)\end{array}$ \\
\hline Italy & $\begin{array}{c}0.286^{\dagger} \\
(0.016)\end{array}$ & $\begin{array}{c}0.308^{+} \\
(0.012)\end{array}$ & $\begin{array}{c}0.237^{\dagger} \\
(0.010)\end{array}$ \\
\hline Portugal & $\begin{array}{c}0.255^{\dagger} \\
(0.014)\end{array}$ & $\begin{array}{c}0.279^{\dagger} \\
(0.010)\end{array}$ & $\begin{array}{r}0.218^{\dagger} \\
(0.010)\end{array}$ \\
\hline Spain & $\begin{array}{c}0.284^{\dagger} \\
(0.010)\end{array}$ & $\begin{array}{r}0.250^{\dagger} \\
(0.008)\end{array}$ & $\begin{array}{r}0.248^{\dagger} \\
(0.008)\end{array}$ \\
\hline Sociodemographic Controls & Yes & Yes & Yes \\
\hline Labor Force Controls & Yes & Yes & Yes \\
\hline $\mathrm{N}$ & 26,892 & 32,468 & 26,907 \\
\hline Psuedo $R^{2}$ & 0.326 & 0.305 & 0.297 \\
\hline
\end{tabular}

Notes: All models control for self-reported health. Survey round controlled for in all models. Reference is average of all countries in the model. Survey weights used. Standard errors clustered by country.

$+p<0.01$. 
will influence the "average" used as the point of reference. It therefore may be instructive to explore how countries fare "head to head," that is how residence in one country increases the likelihood an individual reports a disability relative to another country, net of individual level characteristics. If there is a real difference in the odds of reporting a disability across welfare state regime types, we should expect to find that when compared to residents of other European countries, residents of Nordic nations have consistently higher odds of reporting a disability.

To do this I estimated 105 discrete regression models, one for every possible two-way combination of the 15 nation states included in this study. The full set of individual level sociodemographic and labor force covariates is included in each model. The results of these "head to head" comparisons are presented in Table 5. The table can be read similar to a standard correlation matrix, with the numbers in each cell corresponding to the odds ratio of the country listed on the left hand column relative to the country listed in the top row. The pattern is evident: in a head to head comparison, no country in Europe posts higher odds of reporting a disability than any of the four Nordic countries. Only the Netherlands comes close, achieving statistical parity with Finland. Once again, residents of southern European nations have consistently lower odds of reporting a disability, regardless of the comparison country.

Finally, as detailed above, the dichotomous measure for disability used throughout these analyses collapses those who report being hampered "to some extent" with those who report being hampered "a lot" in their daily activities. It is therefore worthwhile to test whether the observed pattern holds when the measure is constructed so that only those who report being hampered "a lot" are classified as disabled. This might be considered a more conservative test of the proposed relationship between welfare state context and self-reported disability, given that there is likely to be greater consensus across countries on what individuals consider to be severely disabling (relative to what is somewhat disabling). Analyses using this indicator of severe disability reveal the same association: residents of the Nordic states and the Netherlands are substantially more likely to report-and residents of southern Europe less likely to report-a severe disability than their counterparts in the rest of Europe (see Table B in the online supplement). Notably, in this instance the odds ratios for the liberal countries-particularly the United Kingdom-more closely resemble the Nordic states.

\section{Discussion and Conclusion}

The preceding analysis reveals that residents of northern European states are more likely to report a disability than residents of other European countries and, importantly, demonstrates that this association is not limited to those who currently receive or are likely to receive disability benefits-even highly educated, young, and currently employed workers in the Nordic states and the Netherlands are more likely to report being disabled. This cross-national survey data, coupled with the experimental work of van Soest et al. (2011), provides compelling evidence that welfare state context serves to shape what it means to be disabled, and that 


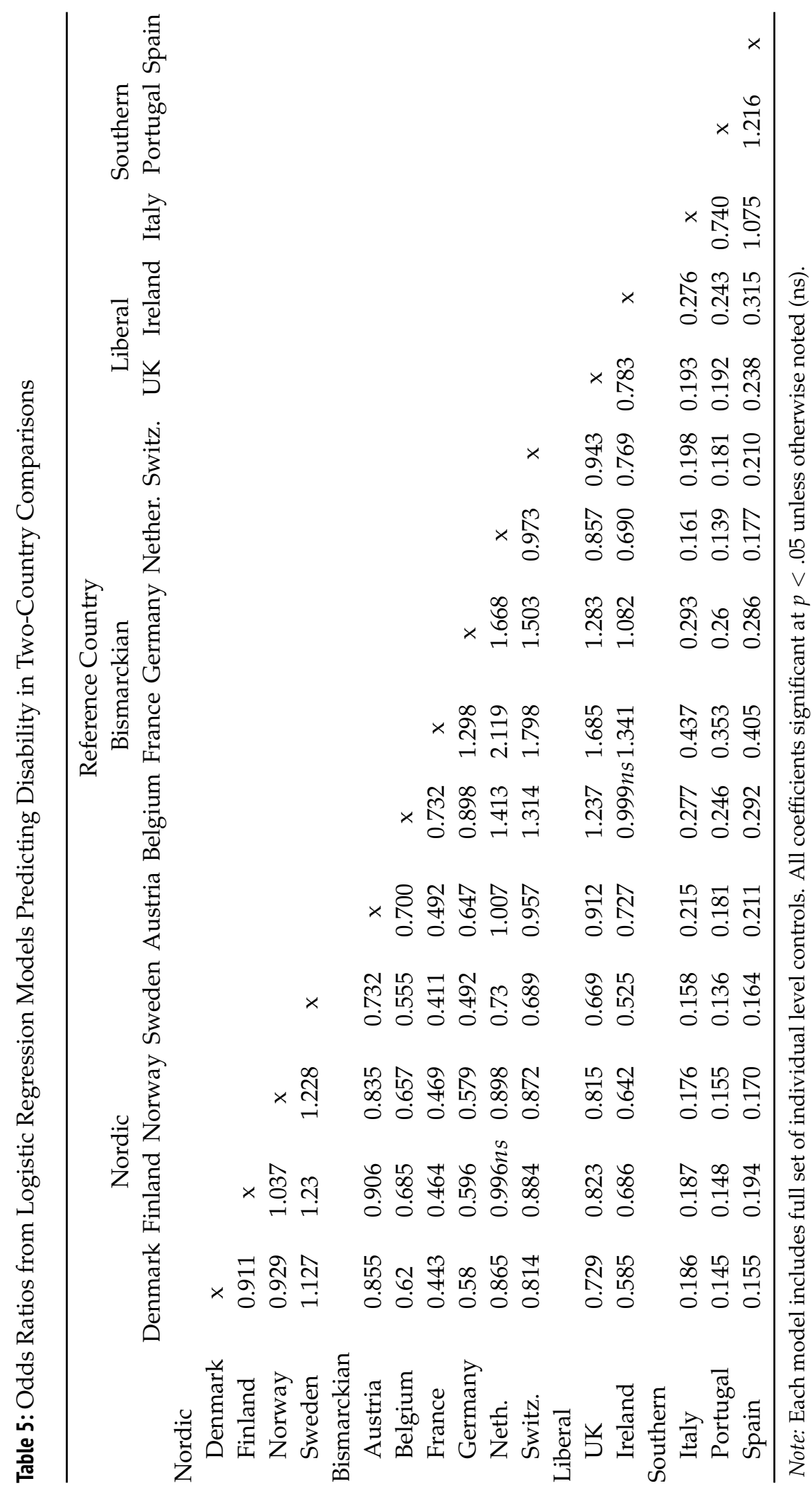


the broader definition extends beyond those who may have a material interest in identifying as having a disability.

It is important to note, however, that data used in this analysis have a number of clear limitations. First, although this study is uniquely focused on self-assessed disability, the lack of additional information on physical and mental health prevents analysis of how welfare state context influences differential reports of specific health conditions, such as back pain or depression. This information would permit a more thorough investigation of the pathways through which welfare state context may be shaping self-reported disability, and, at the same time, help elucidate which health conditions are considered differentially "disabling" across welfare state regimes. Moreover, the cross-sectional nature of the data limits our ability to make causal claims or test how the labor market experiences and life trajectories of individuals interact with welfare state context to produce disability over the life course.

How then do these findings inform our understanding of how welfare state context shapes disability? The results detailed above are consistent with a theory that posits that generous welfare state regimes are associated with an expanded conception of what is considered disabling (as would be inferred from the experimental work of van Soest et al. 2011). However, another interpretation is also plausible. Since the measure of disability used in this (and other) studies of disability is a measure of functional limitation, it could also be that generous welfare state context is associated with an increased willingness or likelihood to report functional limitations precisely because such limitations are not considered to be disabling in those contexts. In other words, it may be the case that functional limitation readily translates into the socially experienced "disability" in less generous welfare state contexts and not in more generous regimes. Given the stigma associated with disability (which itself is likely to vary tremendously across cultures), this may paradoxically result in higher levels of functional limitation being reported precisely in those areas where such limitation does not necessarily mean a disability.

One way to distinguish between these two interpretations of the data may be to investigate the degree to which individual self-reports of functional limitations are associated with social exclusion. If functional limitation is found to be equally predictive of social exclusion across welfare state regime types, we may conclude that generous welfare states are indeed more disabling. If, however, functional limitation is found to be less predictive of social exclusion in generous welfare states than in less generous welfare states, then one may argue that generous welfare states actually disrupt disablement. Future work on disability in cross-national contexts should focus on better understanding what it truly means to be disabled in different context.

Documenting the degree to which welfare state policy contexts reflect and even shift - as argued here-normative assessments of health and disability is fundamental to the project of comparative research on social policy and individual wellbeing. Future research should explore how individual characteristics-including education, family formation, industry (skills and expertise), and labor market historyinteract with welfare state context to increase or decrease the odds that an individual reports a disability. Further, social scientists should employ more nuanced measures of self-perceived disability in order to better appreciate how disability maps onto 
patterns of social exclusion and life trajectories, and how these processes vary by country. The consequences of these cross-national differences in what it means to be disabled-and consequent variation in rates of self-reported disability-remains an open question.

\section{Notes}

1 Calculated using the xi3 package in Stata.

\section{References}

Autor, D. H, and M. G Duggan. 2003. “The Rise In The Disability Rolls And The Decline In Unemployment." Quarterly Journal of Economics 118:157-205. http://dx. doi .org/10. 1162/00335530360535171.

Arts, W., and J. Gelissen. 2002. "Three worlds of welfare capitalism or more? A state-of-theart report." Journal of European Social Policy 12(2):137-158. http://dx . doi .org/10.1177/ 0952872002012002114.

Bell, B., and J. Smith. 2004. Health, disability insurance and labour force participation. Bank of England.

Bambra, C. 2006. "Health status and the worlds of welfare." Social Policy and Society 5(1):53. http://dx.doi.org/10.1017/S1474746405002721.

Borsch-Supan, A. 2007. “Work Disability, Health, and Incentive Effects." MEA Discussion Paper No. 135-07. Available at SSRN: http: //ssrn. com/abstract $\$=\$ 1445367$.

Brady, D., A.S. Fullerton, and J.M. Cross. 2009. "Putting poverty in political context: a multilevel analysis of adult poverty across 18 affluent democracies." Social Forces 88(1):271-299. http://dx.doi.org/10.1353/sof.0.0221.

Bratsberg, B., E. Fevang. 2010. “Disability in the Welfare State: An Unemployment Problem in Disguise?" Institute for the Study of Labor (IZA) Discussion Paper No. 4897..

Chung, H., and C. Muntaner. 2007. "Welfare state matters: a typological multilevel analysis of wealthy countries." Health Policy 80(2):328-339. http://dx. doi .org/10.1016/j . healthpol.2006.03.004.

Coburn, D. 2004. "Beyond the income inequality hypothesis: class, neo-liberalism, and health inequalities." Social Science and Medicine 58(1):41-56. http://dx.doi.org/10. 1016/S0277-9536(03)00159-X.

Conrad, P. and K. Barker. 2010. "The social construction of illness: key insights and policy implications." Journal of Health and Social Behavior 51:67-79. http://dx.doi.org/10. $1177 / 0022146510383495$.

Eikemo, T. A., C. Bambra, K. Judge, and K. Ringdal. 2008. "Welfare state regimes and differences in self-perceived health in Europe: a multilevel analysis." Social Science and Medicine 66(11):2281-2295. http://dx . doi .org/10.1016/j. socscimed . 2008.01.022.

Elwan, A. 1999. Poverty and disability: A survey of the literature. Social Protection Advisory Service, The World Bank. Washington, DC. .

Esping-Andersen, G. 1990. The three worlds of welfare capitalism. Cambridge, UK: Polity Press.

Ferrera, M. 1996. “The 'Southern' Model of Welfare in Social Europe." Journal of European Social Policy 6(1): 17-37. http://dx .doi .org/10.1177/095892879600600102. 
Fitzgerald, R. and R. Jowell. 2011. "Measurement Equivalence in Comparative Surveys: the European Social Survey (ESS) from design to implementation and beyond." Working Paper 3, Centre for Comparative Social Surveys.

Foucault, M. 1963. The birth of the clinic. New York: Vintage Books.

Foucault, M. 1965. Madness and civilization: a history of insanity in the age of reason. New York: Pantheon.

Garfinkel, I., L. Rainwater, and T. M. Smeeding. 2010. Wealth and welfare states: is America a laggard or leader? Oxford University Press.

Goffman, E. 1963. Stigma: Notes on the Management of Spoiled Identity. New York: Simon and Schuster.

Haber, L. D., and R. T. Smith. 1971. "Disability and deviance: Normative adaptations of role behavior." American Sociological Review 36:87-97. http: //dx. doi .org/10.2307/2093509.

Harkness J. A. 2007. “Improving the quality of translations." Pp. 79-94 in Measuring attitudes cross-nationally, edited by R. Jowell et al. London: Sage Publications.

Jenkins, R. 1991. “Disability and social stratification." British Journal of Sociology 42:557-580. http://dx.doi.org/10.2307/591447.

Kapteyn, A., J. P. Smith, and A. Van Soest. 2007. "Vignettes and self-reports of work disability in the United States and the Netherlands." The American Economic Review 97(1):461-473. http://dx.doi.org/10.1257/aer.97.1.461.

Koning, P., and D. Van Vuuren. 2007. "Hidden unemployment in disability insurance." Labour 21(4-5):611-636. http: //dx . doi .org/10.1111/j .1467-9914.2007.00388 . x.

Koning, P., and D. Van Vuuren. 2010. “Disability insurance and unemployment insurance as substitute pathways." Applied Economics 42(5):575-588. http://dx.doi .org/10.1080/ 00036840701704436.

Korpi, Walter and Joakim Palme. 1998. "The Paradox of Redistribution and Strategies of Equality: Welfare State Institutions, Inequality, and Poverty in the Western Countries." American Sociological Review 63(5):661-687. http://dx.doi .org/10 . 2307/2657333.

Korpi, W. 2003. "Welfare-state regress in Western Europe: politics, institutions, globalization, and Europeanization." Annual Review of Sociology 29:589-609. http://dx. doi .org/10. 1146/annurev.soc.29.010202.095943.

Nagi, S. Z. 1965. "Some Conceptual issues in disability and rehabilitation." Pp. 1-13 in Sociology and Rehabilitation, edited by M. B. Sussman. Washington, DC: American Sociological Association.

Nagi, S. Z. 1979. “The concept and measurement of disability.” Pp. 1-15 in Disability Policies and Government Programs, edited by E. D. Berkowitz. New York: Praeger.

Olsen, K. M., and S. AA. Dahl. 2007. "Health differences between European countries." Social Science and Medicine 64(8):1665-1678. http: //dx. doi .org/10.1016/j . socscimed. 2006. 11.031.

Oliver, M. 1990. The politics of disablement. New York: Palgrave Macmillan.

OECD. 2009. OECD Factbook 2009: economic, environmental and social statistics. Paris: OECD.

OECD. 2010. Sickness, Disability and Work: Breaking the Barriers: a Synthesis of Findings Across OECD Countries. Paris: OECD.

Parsons, T. 1975. "The sick role and the role of the physician reconsidered." The Milbank Memorial Fund Quarterly Health and Society 53:257-278. http://dx.doi.org/10.2307/ 3349493.

Parsons, T. 1949. The Structure of Social Action. Glencoe, IL: Free Press of Glencoe. 
Rege, M., K. Telle, and M. Votruba. 2009. "The effect of plant downsizing on disability pension utilization." Journal of the European Economic Association 7:754-785. http: //dx.doi.org/10.1162/JEEA.2009.7.4.754.

Saint-Paul, G. 2004 "Why are European Countries Diverging in their Unemployment Experience?" Journal of Economic Perspectives 18(4):49-68.

Skocpol, T. 1995. Protecting soldiers and mothers: The political origins of social policy in the United States. Cambridge, MA: Belknap Press.

Stone, D.A. 1984. The disabled state. Philadelphia: Temple University Press.

Van Soest, A., T. Andreyeva, A. Kapteyn, and J.P. Smith. 2011. Self reported disability and reference groups. Cambridge, MA:National Bureau of Economic Research. http://dx . doi . org/10.3386/w17153.

Varul, M. Z. 2010. “Talcott Parsons, the Sick Role and Chronic Illness." Body and Society 16(2):72-94. http://dx.doi.org/10.1177/1357034X10364766.

Verbrugge, L. and A. Jette. 1994. "The disablement process." Social Science and Medicine 38(1):1-14. http://dx.doi.org/10.1016/0277-9536(94)90294-1.

Wacquant, L. 2001. “Deadly symbiosis.” Punishment and Society 3(1):95. http://dx. doi .org/ $10.1177 / 14624740122228276$.

World Health Organization. 2008. Global Burden of Disease: 2004 update. Geneva: WHO.

Acknowledgements: The author would like to thank Sara McLanahan, Scott Lynch, Katherine Newman, Viviana Zelizer, Sarah Brayne, and David Pedulla and the editors of Sociological Science for their helpful feedback.

Rourke L. O'Brien: Harvard Center for Population and Development Studies, Harvard University. E-mail: robrien@hsph.harvard.edu. 